Dossiê: Mulheres e violência

\title{
Mulheres como autoras de violência Evidências e agenda de pesquisa
}

\section{Women as authors of violence}

Evidences and research agenda

Hermílio Santos*

Resumo: O artigo destaca a pouca atenção dada, na sociologia brasileira, ao envolvimento de mulheres na criminalidade e em ações violentas, explorando possíveis razões para essa negligência. Parte significativa dos estudos que se dedicam a analisar a participação de mulheres na criminalidade chegam à conclusão que esse envolvimento se dá em condições de subordinação a um parceiro masculino ou assumindo papéis secundários determinados por homens. Com evidências de pesquisa em andamento, chega-se a resultados distintos de boa parte da literatura disponível. Com base na abordagem teórico-metodológica de narrativas biográficas, identificase uma maior variedade de papéis assumidos por mulheres em crimes e em ações violentas.

Palavras-chave: Mulheres. Violência e crime. Narrativas biográficas.

Abstract: The article points out the lack of attention given by the Brazilian sociology to the involvement of women in crime and violent action, exploring possible reasons for that. A great part of studies analyse the participation of women in criminality and violent action come to the conclusion that this involvement occurs under the subordination to a male partner or assuming secondary roles determined by men. Based on findings of on-going researches, it comes to other results than those available in the sociological literature. Based on the biographical narrative approach, it comes to a variety of roles played by women in crime and violent actions.

Keywords: Women. Violence and crime. Biographical narratives.

* Doutor em Ciência Política pela Freie Universität Berlin (Alemanha), professor do PPG em Ciências Sociais da Pucrs em Porto Alegre, RS, Brasil, coordenador do Centro de Análises Econômicas e Sociais da mesma universidade e vice-presidente do Comitê de pesquisa "Biografia e Sociedade", da International Sociological Association(ISA)<hermilio@pucrs.br>. Artigo desenvolvido como parte de pesquisa financiada pelo CNPq (Bolsa Produtividade). 


\section{Introdução}

A literatura sociológica brasileira apresenta relativamente pouco interesse em analisar a participação de mulheres em eventos violentos. De acordo com dados do Conselho Nacional de Justiça, em 2013, o Brasil contava com cerca de 570.000 presos (CNJ, 2014), ${ }^{1}$ dos quais 37.000 mulheres, ou seja, $6,4 \%$ do total da população carcerária. Já no período entre 2000 e 2014 houve um aumento de $567 \%$ na população de mulheres encarceradas, enquanto o crescimento da população carcerária geral foi de 119\% (Ministério da Justiça, 2015). Essa participação crescente de mulheres em crimes já seria motivo suficiente para que a sociologia se debruçasse com mais frequência sobre esse fenômeno, mas não o único. O presente artigo aborda o envolvimento de mulheres em crimes e ações violentas, justificando os motivos pelos quais a sociologia deveria se dedicar de maneira mais sistemática ao problema. A partir de resultados de pesquisas recentes conduzidas pelo autor pretende-se demonstrar que a negligência da sociologia brasileira em relação à participação de mulheres em ações violentas não é fruto de conhecimento consolidado sobre o tema, que justificaria a pouca atenção dada ao problema discutido aqui. Para além disso, o artigo propõe um diálogo com aqueles autores que explicitamente se detiveram ao tema da participação de mulheres em crime e violência e que chegaram à conclusão de que, em geral, a participação das mulheres nesses casos tende a ser secundário ou dominado pela figura masculina. Como se verá na última parte do artigo, resultados preliminares de pesquisa apontam para a existência de uma variedade de papéis assumidos por mulheres em ações violentas, distinguindo-se de parte da literatura mais influente sobre o tema.

\section{Mulheres e violência}

A literatura sociológica sobre violência no Brasil permite indicar, por um lado, que privilegia-se, com poucas exceções (Silva, 2004; Porto, 2006, dentre outros), tratar o tema a partir de uma perspectiva "judicializada", na medida em que a referência ao conceito de violência remete quase sempre ao rompimento de normas e regras legais e às políticas de segurança e administração da justiça, ainda que em trabalhos empíricos sobre o tema, "violência" não seja, em geral, tematizada de maneira explícita. Com isso, as discussões sobre crime na produção sociológica acabam por prevalecer

\footnotetext{
${ }^{1}$ Em junho de 2014, o CNJ informou que o total de detentos no Brasil chegava a 715.655, considerando aqueles que se encontram em penitenciárias e em prisão domiciliar.
} 
sobre a problematização da violência. Os termos "adolescentes infratores", "jovens em conflito com a lei" e "delinquência juvenil", ao tratar de violência praticada por jovens, por exemplo, são expressão da ênfase dada aos aspectos normativos da vida social, ou, de maneira mais precisa, ao controle social. A ênfase a aspectos criminológicos ao abordar o tema da violência explica, em parte, a pouca atenção dada à mulher como autora de violência, tendo em vista que, de acordo com as estatísticas disponíveis, a mulher representa, de fato, uma pequena parcela de autores de crimes, ainda que os dados apontem para um crescimento, em números absolutos, do encarceramento de mulheres nos últimos anos, como já mencionado. Nesse sentido, parte da sociologia brasileira reproduz o que Bertaux (2014) denomina de "ilusão cientificista", que é estabelecer como critério para escolha de temas a serem investigados somente aqueles apontados como estatisticamente expressivos. Portanto, essa combinação de privilegiar a maior recorrência de fenômenos como precondição para seu estudo com o fato de haver ênfase sobre um tipo de violência, o homicídio, contribuem para tornar a mulher praticamente invisível como autora em estudos sobre violência.

Outros componentes do fenômeno da violência em geral são negligenciados na sociologia brasileira, notadamente aqueles que antecedem a uma relação objetiva com as normas legais vigentes. Violência pressupõe uma interpretação subjetiva da realidade, assim como uma relação singular com "o outro", o que nas diferentes abordagens normativas está apenas implícito. Atribuir à violência uma dimensão de alteridade é não apenas compreendêla como uma ação contra a ordem, mas também, simultaneamente, contra "o outro", na medida em que implica em "uma restrição ou destruição assimetricamente imposta" (Staudigl, 2007, p. 245) das possibilidades de ação do outro. Como qualquer ação social, violência implica na existência da possibilidade de escolha em um contexto de relações entre sujeitos, no qual a assimetria se constitui como elemento orientador das interações. A assimetria não é dada a priori e de maneira reificada, mas implica em um processo de construção a partir das interpretações conduzidas pelos próprios sujeitos envolvidos em atividades interativas. Portanto, as possibilidades de ação violenta não estão fixa e estaticamente determinadas, nem pela posição social, nem pelo gênero, nem por qualquer outra característica objetiva que se possa atribuir ao ator. Adotar uma perspectiva analítica que explore a subjetividade dos agentes implica em conceder ao indivíduo um status de ator que interpreta os "objetos" com os quais está confrontado (pessoas, ideias, acontecimentos, valores etc.), a fim de se posicionar no mundo e, com isso, estabelecer seu 
próprio roteiro de ação. O pressuposto aqui é de que o ator social não é um mero internalizador de normas e de significados socialmente difundidos; ao contrário, esse ator é, segundo Arthur S. Parsons, um agente consciente e responsável pela adoção ativa de códigos normativos na interpretação da realidade social (Parsons, 1978, p. 111).

Caso se amplie os horizontes de investigação para abranger não apenas crime, mas todas e quaisquer expressões de violência, será possível verificar que a sociologia tem, de fato, negligenciado injustificadamente a investigação sobre o envolvimento de mulheres em ações violentas. E ao fazê-lo estar-seia contribuindo para que o problema permaneça parcialmente compreendido, tendo em vista que, como pesquisas recentes vem revelando, não se trata de um tipo de ação exclusivo do gênero masculino.

Em pesquisa conduzida pelo autor entre 2012 e 2014 sobre violência contra crianças em favelas do Rio de Janeiro, Recife e São Paulo (Santos, 2014), ${ }^{2}$ verificou-se que tanto meninos quanto meninas sofrem violência com frequências semelhantes. A figura 1 apresenta os dados consolidados do questionário aplicado a 480 crianças de 6 a 8 anos de idade em 15 favelas/ comunidades dessas cidades. Sem diferença estatisticamente significativa, a frequência com que meninos e meninas sofrem violência física ("bater") dentro de casa é semelhante. Cabe observar que $67 \%$ dos respondentes, tanto de meninos quanto de meninas, afirmam sofrer violência física dentro de casa, por outro lado, a frequência com que sofrem violência física "muitas vezes" é ligeiramente maior entre as meninas (29\%) se comparado com os meninos (24\%) de 6 a 8 anos de idade. ${ }^{3}$

\footnotetext{
${ }^{2}$ A pesquisa, financiada pela Fundação Bernard van Leer (Holanda), contou com a participação de equipes em Porto Alegre, Recife, Rio de Janeiro e São Paulo. No Rio de Janeiro a pesquisa foi realizada em parceria com o Central (Centro de Pesquisa da Cidade da PUC-Rio), em Recife foi conduzida em parceria com o Núcleo de Estudos e Pesquisas em Criminalidade, Violência e Políticas de Segurança (UFPE) e em São Paulo o autor contou com a colaboração do departamento de Ciências Sociais da PUC-SP.

3 A preparação dos questionários, bem como o cruzamento e consolidação dos resultados dos questionários aplicados a crianças e adultos, pais ou responsáveis de crianças, ficou sob a responsabilidade de Celina de Pinho Barroso (Doutoranda no Propur/Ufrgs), a quem agradeço pela colaboração com a equipe do Centro de Análises Econômicas e Sociais (CaesPucrs).
} 
Figura 1. Violência física (bater) sofrida pela criança em casa, por sexo Percepção da criança. Rio de Janeiro, Recife (2012) e São Paulo (2013)

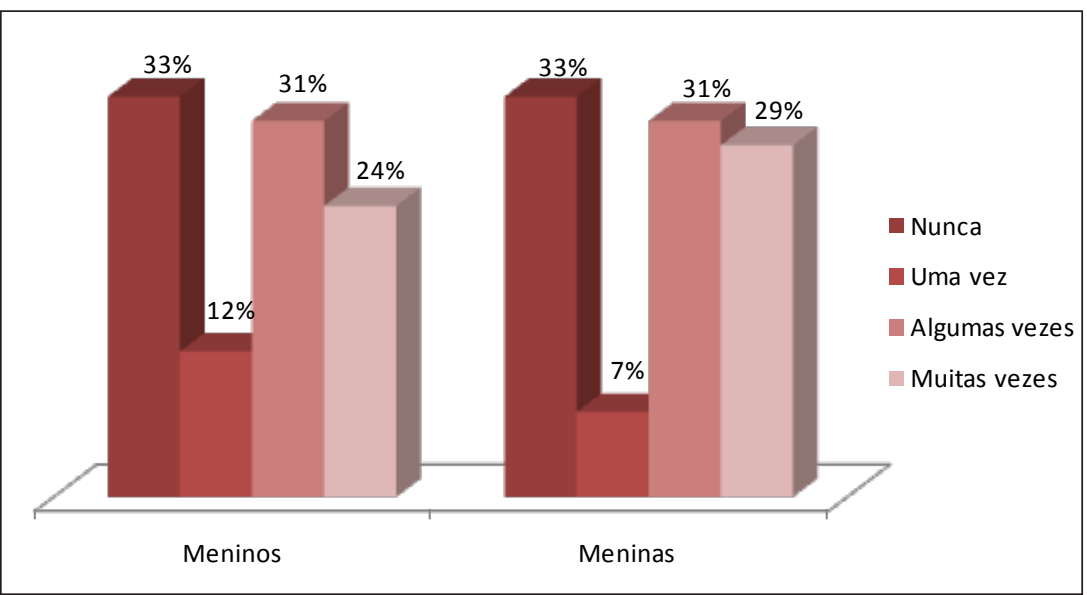

Nota: Os dados foram obtidos em questionários aplicados a crianças de 6 a 8 anos de idade $(\mathrm{n}=480)$ nas seguintes comunidades/favelas do Rio de Janeiro, Recife e São Paulo entre 2012 e 2014: Morro da Formiga, Morro dos Macacos, Vila Cruzeiro, Parque Maré, Minha Deusa (RJ) e Mangueirinha (Duque de Caxias); Canal do Arruda, Chão de Estrelas e Santo Amaro (Recife); Jardim Pantanal, Parelheiros, Pedreira, Santa Cecília, Bela Vista (SP) e Pimentas/Água Chata (Guarulhos). Nas regiões de Santa Cecília e Bela Vista, foram entrevistadas crianças moradoras de cortiços (também conhecidos como "pensões").

De acordo com a figura 2, com base nas respostas dadas por adultos responsáveis por crianças de 0 a 8 anos de idade, a mãe aparece como a principal autora de violência física contra crianças em casa. Mais da metade (65\%) das mães afirmam praticar violência física contra os filhos com alguma frequência ("raramente", "às vezes", "quase sempre" e "sempre"). Por outro lado, 48\% das avós praticam violência física contra os netos sob sua responsabilidade, enquanto $39 \%$ dos pais admitem praticar violência contra crianças de 0 a 8 anos de idade. Sem poder avançar aqui a análise de hipóteses que faz da mãe a principal autora de violência, cabe destacar que o fato de a mãe ser o membro da família que mais tempo fica com a criança não explica completamente a prevalência da mulher como aquela que mais pratica violência contra a criança, se comparado com o pai e a avó, tendo em vista que as mães que ficam menos tempo com as crianças praticam violência contra os filhos em frequência superior àquelas que passam mais tempo. Os resultados obtidos na pesquisa não sugerem que o pai tenderia a ser pacífico, mas que haveria o que poderíamos denominar de "hierarquia da violência", em que o pai tende 
a praticar violência com mais frequência contra a companheira e esta, por sua vez, pratica a violência contra os próprios filhos, sugerindo uma configuração própria de sociedades autoritárias, o que parece corroborar alguns autores que trataram do tema (por exemplo, Saffioti, 1999).

Figura 2. Violência física praticada contra crianças por grupo de adultos

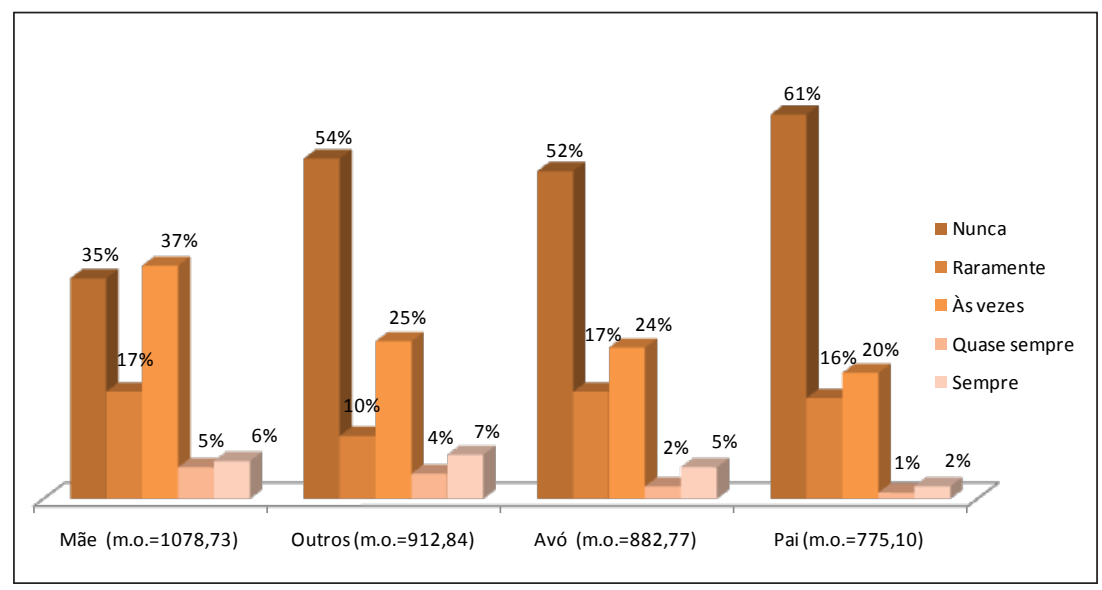

Nota 1: Os dados foram obtidos em questionários aplicados a pais ou responsáveis $(\mathrm{n}=2.012)$ por crianças de 0 a 8 anos de idade nas seguintes comunidades/favelas do Rio de Janeiro, Recife e São Paulo entre 2012 e 2014: Morro da Formiga, Morro dos Macacos, Vila Cruzeiro, Parque Maré, Minha Deusa (RJ) e Mangueirinha (Duque de Caxias); Canal do Arruda, Chão de Estrelas e Santo Amaro (Recife); Jardim Pantanal, Parelheiros, Pedreira, Santa Cecília, Bela Vista (SP) e Pimentas/Água Chata (Guarulhos). Nas regiões de Santa Cecília e Bela Vista, foram entrevistadas crianças moradoras de cortiços (também conhecidos como "pensões").

Nota 2: m.o.=médias dos valores ordinais dos grupos que permitem identificar, neste caso, qual deles mais bate na criança. Foram obtidas através do teste não-paramétrico Kruskal-Wallis. Os valores mais altos indicam grupos que batem com maior frequência e os valores mais baixos indicam os grupos que batem em frequência menor. Diferença estatisticamente significativa $\left(\mathrm{K}-\mathrm{W}, \mathrm{chi}^{2}=81,842\right.$, sig $\left.=0,000\right)$.

Cabe destacar outro dado obtido na pesquisa mencionada, que é a idade e a frequência com que crianças de 0 a 8 anos de idade sofrem violência física, tendo a mãe como autora dessa violência. Observa-se que as crianças muito pequenas, já a partir de um ano de idade, começam a ser alvo de violência física, cujo pico ocorre contra crianças de cinco e três anos de idade (figura 3), em que $76 \%$ das mães de crianças de 5 anos de idade admitem bater em seus filhos dessa idade com alguma frequência. Mais de $70 \%$ das mães com crianças de 2 a 8 anos de idade admitem praticar violência contra seus filhos com alguma frequência. Desde muito cedo, portanto, a criança 
Figura 3. Idade das crianças e frequência da violência física contra crianças praticada pelas mães

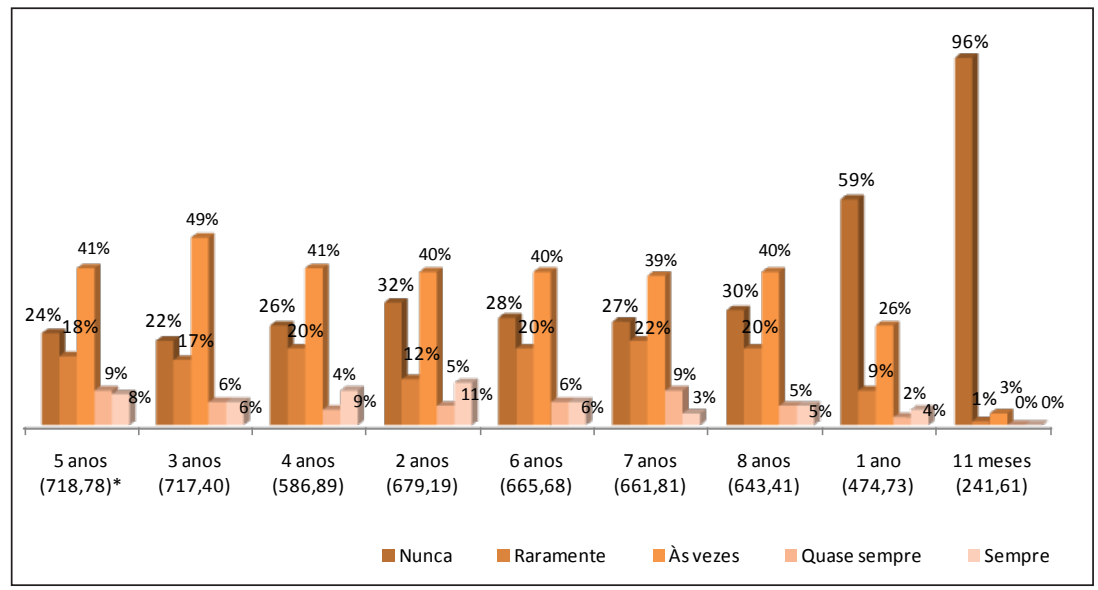

Nota 1: Os dados foram obtidos em questionários aplicados a mães $(\mathrm{n}=1.257)$ de crianças de $0 \mathrm{a}$ 8 anos de idade nas seguintes comunidades/favelas do Rio de Janeiro, Recife e São Paulo entre 2012 e 2014: Morro da Formiga, Morro dos Macacos, Vila Cruzeiro, Parque Maré, Minha Deusa (RJ) e Mangueirinha (Duque de Caxias); Canal do Arruda, Chão de Estrelas e Santo Amaro (Recife); Jardim Pantanal, Parelheiros, Pedreira, Santa Cecília, Bela Vista (SP) e Pimentas/ Água Chata (Guarulhos). Nas regiões de Santa Cecília e Bela Vista, foram entrevistadas crianças moradoras de cortiços (também conhecidos como "pensões").

Nota 2: m.o.=médias ordinais que permitem identificar, neste caso, qual deles mais bate na criança. Foram obtidas através do teste não-paramétrico Kruskal-Wallis. Os valores mais altos indicam mães que batem com maior frequência e os valores mais baixos indicam mães que batem com menos frequência. Diferença estatisticamente significativa $\left(\mathrm{K}-\mathrm{W}, \mathrm{chi}^{2}=161,605, \mathrm{sig}=0,000\right)$.

passa por uma socialização violenta, sendo esta prática incorporada como uma forma de resolução de conflito e expressão de procedimentos para se ajustar comportamentos não-desejáveis de crianças. Esses resultados sugerem que, no Brasil, antes e para além de se constituir em um problema, inequívoco, de desigualdade de gênero, a violência praticada com tal frequência contra pessoas com tão pouca idade expõe uma sociedade marcadamente autoritária. Utilizou-se aqui deliberadamente a referência à violência contra pessoas de pouca idade, tendo em vista que o termo "violência contra criança", como usualmente utilizado, parece contribuir para legitimar a percepção difundida de que "tapas", "palmadas" e outras modalidades de agressão física que tem a criança como alvo faria parte de um processo, supostamente necessário, de ajustamento de comportamentos inadequados de pessoas com pouca idade. Nesse sentido, a assimetria nas interações do cotidiano 
é elemento constituinte do emprego da violência de uns em relação a outros, estes últimos percebidos como mais fracos ou inferiores. Alguns autores interpretam esse processo de violência da mãe contra os filhos, seja como uma expressão da chamada "síndrome do pequeno poder", seja como uma delegação do homem, chefe do grupo familiar (Saffioti, 1999, p. 84). Esse tipo de interpretação lida basicamente com a ideia de que a violência é eminentemente masculina e que a ação violenta praticada por mulheres seriam ou por desvio ou por delegação do homem. Os dados apresentados até aqui, a análise de narrativas de biografias de jovens autoras de violência, que se fará a seguir, assim como o conceito de violência assumido nesse artigo, evidentemente não colocam em questão a assimetria de gênero existente na sociedade brasileira. Contudo, não permitem sustentar a ideia de que as mulheres estariam incapacitadas, por conta e vontade próprias, de agir com violência.

A pesquisa apontou ainda, a partir da análise de narrativas biográficas com membros de duas a três gerações de uma mesma família, que as experiências de violência no contexto familiar e extrafamiliar não são reproduzidas automaticamente de uma geração a outra, havendo diversas trajetórias e dinâmicas biográficas em relação ao envolvimento dessas mulheres com ações violentas. $^{4}$

No Brasil, os estudos disponíveis relacionando mulher e violência podem ser divididos em dois grupos: o primeiro deles se dedica exclusivamente a analisar o problema da violência contra a mulher, que compõe uma vasta produção na literatura sociológica (por exemplo, Saffioti, 2001; Kronbauer e Meneghel, 2005; Pasinato, 2006; 2010; Debert e Gregori, 2008; Ratton Jr. et al., 2011; Vasconcellos, 2013, dentre inúmeros outros). Aqui, a discussão sobre as diferenças e as desigualdades de gênero ganham um destaque na discussão; o segundo grupo, menos frequente, identifica o papel da mulher em ações violentas como sendo subordinado ao protagonismo masculino ou seduzido por um "ethos da masculinidade" (ver por exemplo, Zaluar, 1999), seja agindo sob o comando masculino, seja mimetizando uma atitude tipicamente masculina. No trabalho de Carlos A. Teixeira Magalhães (2008) - realizado com entrevistas com roteiro estruturado e atendo-se aos argumentos apresentados pelas entrevistadas -, poucas foram aquelas que admitiram envolvimento na criminalidade de maneira autônoma, ou seja, sem dependência em

\footnotetext{
${ }^{4}$ Os relatórios da pesquisa estão disponíveis em <ww.pucrs.br/caes>, em "Pesquisas concluídas". Para a análise de narrativas biográficas, ver "Relatório Síntese Rio de Janeiro", no mesmo endereço de Internet. Está previsto para 2016 a publicação de livro com a síntese dos resultados desta pesquisa.
} 
relação à figura masculina. Zaluar, por sua vez, explora o que ela denomina "ethos da masculinidade" como um elemento catalisador do envolvimento de mulheres em ações criminosas (Zaluar, 1999). Nessa literatura, o tema de gênero ocupa um espaço relativamente menor na discussão dos resultados obtidos.

Mais recentemente, pode-se identificar um crescente interesse em estudos que apontam para diferentes formas de protagonismo feminino em ações violentas e envolvimento em crimes. Michaela Köttig (2004), por exemplo, analisa as dinâmicas biográficas e familiares de mulheres envolvidas em movimentos de extrema direita e neonazistas na Alemanha. No Brasil, encontram-se estudos que destacam o envolvimento de mulheres no tráfico de drogas, em especial nas favelas do Rio de Janeiro (por exemplo, Barcinski, 2012), nos quais fica evidenciado o processo de dominação de mulheres parceiras de homens traficantes sobre as demais mulheres das comunidades onde atuam. Outros autores brasileiros se dedicaram a analisar crimes cometidos por mulheres, como Magalhães (2008), que explora os argumentos apresentados por elas para justificar seu envolvimento em ações criminosas.

\section{Violência em narrativas biográficas}

Tanto a escassez de pesquisas sobre o envolvimento de mulheres com violência, quanto as conclusões a que chegaram parte das pesquisas disponíveis que exploram esse tema, motivaram empreender esforços para que se pudesse contribuir com o problema em tela. Embora tratar-se de temática poucas vezes analisada por qualquer método disponível, optou-se por investigar o envolvimento de mulheres com ações violentas por meio de narrativas biográficas. O ponto de partida dessa abordagem é fazer com que os entrevistados, no caso aqui, mulheres com experiência direta com violência e crime, ${ }^{5}$ possam contar ao pesquisador toda a sua vida, sem interrupções de perguntas. Embora narrativas biográficas sejam reconhecidas internacionalmente, sendo uma das abordagens de "Biografia e Sociedade", reconhecida pela ISA (International Sociological Association), como também pela ESA (European Sociological Association) e pela DGS (Deutsche Gessellschaft für Soziologie) como uma das subáreas da sociologia, ainda é muito pouco conhecida e reconhecida na sociologia brasileira. Os resultados de mais de três décadas de pesquisas valendo-se de narrativas biográficas demonstram não apenas o potencial

\footnotetext{
${ }_{5}$ A pesquisa, com apoio do CNPq (Bolsa PQ) e da Fapergs/Capes (DocFix), prevê entrevistas com mulheres adultas e adolescentes com experiência direta de violência.
} 
dessa abordagem, mas sobretudo o conhecimento já aportado a temas os mais variados, como migração, desemprego, vítimas e perpetradores do holocausto, dentre inúmeros outros. ${ }^{6}$

$\mathrm{Na}$ pesquisa que vem sendo conduzida com mulheres autoras de violência, adota-se a abordagem de análise proposta por Rosenthal (1995, 2014), cuja principal característica analítica é a distinção entre aquilo que é vivenciado e a narrativa dessa vivência. Para tanto, Rosenthal propõe alguns passos no processo de análise a fim de se obter o máximo do grande volume de "dados" que se obtém de uma entrevista narrativa biográfica, podendo inclusive ser complementada com análise de documentos, quando disponíveis, ou mesmo por outras abordagens, como a observação, a etnografia e a narrativa visual. $^{7}$

O uso dessa abordagem tem permitido chegar a conclusões preliminares distintas de parte daquelas disponíveis quanto ao envolvimento de mulheres em ações violentas e em crimes. Como afirmado anteriormente, a tese corrente é de que a mulher, quando se envolve com crime ou violência o faz não apenas em companhia de um parceiro masculino, mas subordinado a ele, ou então assumindo papéis secundários determinados por um chefe masculino. Tem sido possível encontrar, ao contrário, uma diversidade de papéis assumidos por mulheres, vários deles bastante distintos daqueles que se poderia caracterizar como sendo uma posição subalterna. A diferença de resultados se deve, pelo menos em parte, à diferença de métodos adotados. Na abordagem de narrativas biográficas (Rosenthal, 2014), a análise possibilita considerar todas as informações colhidas durante a entrevista, e não apenas aquelas diretamente relacionadas ao evento criminoso ou violento, nem tampouco tem por objetivo verificar hipóteses previamente formuladas. Um dos principais motivos para se conduzir entrevistas abertas como adotadas em pesquisas narrativas biográficas é o interesse em aproximar-se da gênese das experiências dos entrevistados com os fenômenos pesquisados.

Como se trata de compreender as motivações para o envolvimento de mulheres como autoras em atos de violência e crime, os elementos para essa análise ultrapassam o evento violento ou criminoso. Ancorando-se na sociologia de Alfred Schutz (2003), fala-se aqui em buscar os "motivos porquê", ou seja, aquelas motivações biograficamente registradas ao longo da trajetória de vida da autora de violência e crime. A maneira de se obter acesso a essas motivações

\footnotetext{
${ }^{6}$ A revista $F Q S$, editada há mais de 15 anos, publica artigos com resultados dessas pesquisas.

$7 \mathrm{O}$ autor vem adotando a "narrativa visual" com as mulheres entrevistadas como complemento às narrativas biográficas. Narrativa visual consiste, aqui, em um passeio filmado pela própria entrevistada, com local, tema e duração definidos também pela entrevistada.
} 
está em recorrer às narrativas sobre a vida da entrevistada, considerando-se que nesse procedimento obtêm-se a interpretação da entrevistada sobre sua vivência. Portanto, não se busca obter a vivência mesma, mas a maneira como ela é apresentada hoje e de que maneira experiências passadas podem ter sido vivenciadas na interpretação da entrevistada.

Identificou-se uma variedade de experiências de mulheres como autoras de violência que poderão se configurar em tipos distintos, na medida em que avançar a análise da pesquisa em andamento. Por um lado, já foi possível encontrar experiências que podem ser, de fato, consideradas como sendo daquele tipo descrito na literatura como subordinação ao masculino. Por outro lado, encontramos outros tipos que, aparentemente, pertencem a esse tipo. Contudo, com a análise da narrativa biográfica é possível chegar a conclusões distintas. O pressuposto para se chegar a esse tipo de conclusão é não se ater, na entrevista e na análise, exclusivamente ao evento delituoso ou violento, mas expandir a análise a todas as demais experiências biográficas, como é possível verificar nos casos de Fabíola Costa $^{8}$ (Santos, 2010, p. 152) e Tainá Moreira, apresentados brevemente a seguir.

Fabíola, 16 anos, cumpria medida socioeducativa por ter participado em um latrocínio. Solicitada para que contasse toda sua vida, Fabíola iniciou seu relato aos 12 anos de idade, quando se mudou da casa dos pais para a casa da avó após o assassinato do pai. Na primeira de três entrevistas, Fabíola se deteve em relatar a relação tumultuada com seu namorado e as circunstâncias de sua detenção pela polícia, temas recorrentes nas demais entrevistas. A perda do pai parece ter motivado a busca por uma proteção masculina e a recusa em viver com sua mãe, uma vez que é bastante plausível pensar que a morte do pai pode ter significado a perda da segurança e da proteção em casa, não encarando a mãe como capaz de exercer esse papel. A substituição do pai foi buscada em outra figura masculina: vários adolescentes com os quais manteve algum tipo de envolvimento afetivo ou sexual e posteriormente com seu namorado, com quem manteve uma relação por três anos, e por intermédio de quem iniciou seu envolvimento em atividades delituosas. Fabíola afirma ter tentado se separar do namorado diversas vezes, sem sucesso. Alguns autores poderiam argumentar que se trataria de uma atração por um "ethos da masculinidade". Contudo, os relatos de Fabíola oferecem outros elementos que tornam compreensível a persistência dessa relação com seu namorado, assim como seu engajamento nos crimes cometidos por ele. Embora possa haver uma atração pela figura masculina no caso da Fabíola, ao ponto mesmo que

\footnotetext{
${ }^{8}$ Os nomes verdadeiros foram substituídos para preservar a identidade das entrevistadas.
} 
se poderia ficar com a impressão de que ela teria abdicado de suas ambições e julgamentos individuais para assumir aqueles do seu parceiro, não parece ser exatamente o caso da Fabíola e de outras entrevistadas. A ideia de uma atração pelo masculino parece minimizar a tese de que a associação a uma figura masculina pode envolver igualmente um certo cálculo, em que a parceria poderia fornecer algumas vantagens. Nesse caso, a aliança com seu namorado permite que Fabíola possa sair de casa, o que era seu principal objetivo após a morte do pai. Com isso, a parceria entre Fabíola e seu namorado envolve não necessariamente subordinação a uma figura masculina, mas sobretudo um cálculo de suas vantagens, mesmo que isso implique assumir alguns riscos e, eventualmente, pagar um preço elevado. Durante a entrevista, Fabíola demonstra ter se dado conta de que o preço dessa aliança foi demasiadamente elevado, o que ajuda a compreender as razões pelas quais a entrevistada dedica boa parte de sua entrevista expondo seu descontentamento em relação ao ex-namorado. Contudo, após as primeiras vezes em que acompanhou o namorado em assaltos percebeu que havia um risco bastante reduzido de ser presa e punida. Esta maneira de pensar é comum por parte do senso comum para se orientar no cotidiano, como afirmado por Schutz (2003), de que está convencido de que "se assim foi, assim poderá ser no futuro". Em outras palavras, se os primeiros delitos ocorreram sem qualquer consequência negativa o mesmo poderia continuar ocorrendo no futuro. Fabíola deixa isso claro na seguinte passagem:

... eu tinha medo, tive medo na primeira vez, e na segunda vez. Então, na terceira eu não tinha mais medo. Eu pensei que tudo sairia bem. Se a primeira e a segunda vez foi tudo bem, por que alguma coisa ia sair mal na terceira. E as coisas aconteceram assim. (Transcrição de entrevista com Fabíola Costa, 16 anos)

Esta forma de organizar as ações, ou seja, de considerar o estoque de experiências como um critério para definir ações futuras já havia sido apontado por Schütz como uma maneira sistemática adotada pelo senso comum nas rotinas do cotidiano. A compreensão do envolvimento de Fabíola em atos delituosos torna-se mais plausível por meio da interpretação de sua própria experiência, explícita em sua narrativa, uma vez que a fundamentação para sua ação pode ser encontrada nela mesma. Nesse sentido, parece que a atração por uma figura masculina não é suficiente para se compreender seu engajamento em delitos e atos de violência, como latrocínio. Essa atração estava combinada com uma racionalização sobre como os eventos ocorrem na vida cotidiana. Ter sido apreendida pela polícia após o assassinato de um taxista que havia sido 
assaltado deu a ela um novo conhecimento sobre a vida cotidiana: o futuro é algo distinto de uma simples repetição de eventos passados.

Outro tipo de experiência com violência é ilustrada por Tainá Moreira, que aos 13 anos se envolveu no assassinato de outra adolescente. ${ }^{9}$ Atendendo a um pedido de Tainá, Cláudio executou sua prima, Verônica. O crime havia sido detalhadamente planejado por Tainá em cartas trocadas com Cláudio. O interesse de Cláudio no assassinato de sua prima era poder manter um relacionamento com Tainá e a condição imposta por ela era de que eliminasse sua prima, com quem Tainá já havia tido diversas brigas durante a adolescência.

Tainá cresceu em um ambiente doméstico marcado fortemente por princípios religiosos rigorosos - especialmente observados pela mãe - e por violência e negligência, com os pais brigando entre si. Portanto, Tainá recebeu mensagens contraditórias dos pais, combinando moral religiosa como orientação para o comportamento cotidiano com disputas físicas entre o casal. Em uma dessas brigas, o pai foi hospitalizado por algumas semanas em razão dos ferimentos provocados pela mãe. Ao mesmo tempo, sendo a filha mais velha, Tainá passou a ter que assumir responsabilidades nos cuidados com o irmão mais novo, o que pode ter estimulado sentimentos de vingança contra ele.

Durante sua apresentação inicial, Tainá relata que foi estuprada aos 10 anos de idade por um amigo do seu pai. Esse tema é central em sua apresentação, muito provavelmente como uma forma de emoldurar a situação de negligência vivida por ela dentro de casa. A negligência, nesse caso, é indicada pelo fato do homem que a abusou ser amigo do pai e também pelo fato da mãe, em duas ocasiões, não ter tomado as atitudes que Tainá esperava: certificar-se de que o sangue em sua roupa íntima no dia do estupro não era de ferimentos provocados por um acidente de bicicleta, como alegara à mãe, e ter apresentado uma denúncia à polícia quando soube do caso três anos após o ocorrido. Diante da inação dos pais em relação ao homem que a havia estuprado, Tainá planejou que iria matá-lo ou pelo menos deixá-lo incapacitado para andar. Para esse crime, Tainá contaria novamente com a ajuda do Cláudio, que deveria fornecer a arma, mas sua execução ficaria sob a responsabilidade de Tainá, sem transferi-la para Cláudio.

Simultaneamente a essa apresentação de um contexto de negligência e vitimização, Tainá expõe os diversos eventos nos quais exerceu um papel ativo

\footnotetext{
${ }_{9}$ Agradeço a colaboração de Odil Matheus Fontella e Luana Machado para a reconstrução biográfica da Tainá.
} 
em ações violentas, não apenas contra Verônica, sua amiga de infância, como também contra sua irmã e seu irmão, ambos mais novos que ela. Os irmãos foram vítimas de Tainá em graus variados de violência, em que o irmão foi alvo das práticas as mais violentas, já que aos dois anos de idade Tainá tinha costume de enforcá-lo com as mãos em momentos de irritação e em outros por pura diversão. ${ }^{10}$

Seu roteiro de ação pode ser caracterizado, portanto, a partir de uma compreensão da violência como uma possibilidade de obstruir, parcial, temporária ou definitivamente, a existência do outro. Ainda que reconheça a assimetria na sua relação com outras pessoas, esta não é assumida por Tainá como reificada e, portanto, pode ser modificada dependendo do tipo de recursos à disposição e alianças que fizer para interagir com o alvo potencial de sua ação violenta. Desta maneira, Tainá articula-se para reverter aquelas situações em que se encontrava em desvantagem, como em relação a Verônica e ao homem que a estuprou. Nas situações em que Tainá se reconhecia em posição de vantagem, não foi mobilizado nenhum tipo de aliança ou ajuda para perpetrar ações violentas.

Assim como Tainá, diversas outras adolescentes já entrevistadas apresentam biografias com experiência como autoras de ações violentas, não apenas em eventos criminosos. O que é muito comum em praticamente todas as adolescentes entrevistadas até o momento é que os crimes são cometidos quase sempre em parceria com um parceiro masculino. Esse tipo de parceria conduziu a diversos pesquisadores a classificar a posição das mulheres como sendo subalternas ao parceiro, afetivo ou não. Contudo, os relatos de suas histórias de vida e a análise de suas narrativas biográficas têm permitido encontrar uma variedade de papéis exercidos por mulheres em ações criminosas e atos de violência, em que a subordinação ao homem é apenas um deles. As pesquisas em andamento se ocupam em analisar a variedade desses papéis ocupados pelas mulheres em ações violentas com o objetivo de compreender a complexidade e pluralidade desse fenômeno na sociedade brasileira contemporânea.

\section{Conclusão}

Percebe-se que o envolvimento de mulheres com violência não se dá, nos casos analisados até o momento, mediante uma dicotomia entre vítimas e protagonistas. Em todos os casos de protagonismo observados até o momento,

${ }^{10}$ Uma apresentação mais completa do caso da Tainá foi feita no $18^{\circ}$ Congresso da ISA, realizado em Yokohama, em julho de 2014. O texto com a reconstrução biográfica de Tainá será publicado em livro. 
as mulheres dispõem igualmente de experiências biográficas como vítimas. Nesse sentido, não é suficiente, caso se queira compreender a participação ativa de mulheres em ações de violência, o fato de já ter sido vítima, tendo em vista que não há uma correlação entre esses dois papéis, pois não há uma conversão automática da condição de vítima em autora.

Como já afirmado, boa parte da literatura disponível sobre o tema afirma que a mulher exerce um papel secundário ou subalterno na prática da violência. Aqui, cabe a ressalva de que nessa literatura, embora não esteja sempre explícito, a menção à violência é quase sempre uma referência à participação de mulheres no cometimento de crimes. Como vimos, se se considerar outras formas de violência, como aquela praticada contra crianças, seria possível verificar que a mulher aparece como aquela que a pratica com maior frequência, sem que haja evidências empíricas capazes de sustentar que esta ação é conduzida por delegação masculina, como afirmam alguns autores (por exemplo, Saffioti, 1999, p. 84). Porém, mesmo se se considerar exclusivamente a prática de crimes, a pesquisa em andamento com narrativas biográficas, até o momento exclusivamente com mulheres adolescentes, também é possível identificar uma variedade maior de tipos de envolvimento de mulheres com crimes do que a literatura disponível apresenta. Muito provavelmente as abordagens metodológicas adotadas nas diferentes pesquisas até agora podem explicar os resultados distintos a que se chega. Embora grande parte, senão a sua quase totalidade, de mulheres adolescentes entrevistadas admitam ter cometido o delito em companhia de um parceiro do sexo masculino, não deverá ser entendido como exercendo um papel secundário ou subalterno. Mesmo nos casos em que, na execução concreta do delito, seja o parceiro homem aquele que empunha a arma ou mesmo que executa o ato delituoso, seria impreciso concluir daí que o papel da mulher seja de menor importância. Isso porque há uma diversidade de papéis sendo executados no cometimento de crimes, inclusive aqueles relacionados ao planejamento e organização dos delitos. Nesse sentido, as narrativas biográficas obtidas até o momento sugerem haver, em alguns casos, um protagonismo maior das mulheres, não apenas restrito ao relato sobre o evento criminoso, mas também sobre a trajetória de vida das entrevistadas. Ao mesmo tempo, pelo menos no caso da Tainá, as narrativas sugerem que as formas de violência empregadas contra o irmão e contra sua ex-colega estão vinculadas de alguma maneira à sua própria experiência biográfica. A ampliação do material a ser analisado, ou seja, relatos sobre eventos biográficos, pode permitir chegar a esse tipo de conclusão, como já vem sendo possível com a realização de entrevistas narrativas biográficas a partir dos procedimentos e análises propostos por Rosenthal (2014). 


\section{Referências}

BARCINSKI, Mariana. Mulheres no tráfico de drogas: a criminalidade como estratégia de saída da invisibilidade social feminina. Contextos Clínicos, v. 5, n. 1, p. 52-61, 2012 $<10.15448 / 1984-7289.2014 .2 .17147>$.

BERTAUX, Daniel. A vingança do curso de ação contra a ilusão cientificista. Civitas, v. 14 , n. 2, p. $250-271,2014<10.15448 / 1984-7289.2014 .2 .17147>$.

CNJ. Do total de 580 mil presos, população carcerária feminina no Brasil é de quase $37 \mathrm{mil}$. 22/08/2013 < http://www.cnj.jus.br/noticias/cnj/60625-do-total-de580-mil-presos-populacao-cerceraria-feminina-no-brasil-e-de-quase-37-mil> (7 ago. 2014).

DEBERT, Guita Grin; GREGORI, Maria Filomena. Violência e gênero: novas propostas, velhos dilemas. Revista Brasileira de Ciências Sociais, v. 23, n. 66, p. 165-211, $2008<10.1590 /$ S0102-69092008000100011>.

KÖTTIG, Michaela. Lebensgeschichten rechtsextrem orientierter Mädchen und junger Frauen - Biographische Verläufe im Kontext der Familien- und Gruppendynamik. Giessen: Psychosozial-Verlag, 2004.

KRONBAUER, José Fernando Dresh; MENEGHEL, Stela Nazareth. Perfil da violência de gênero perpetrada por companheiro. Revista de Saúde Pública, v. 39, n. 5, p. 695-701, $2005<10.1590 / \mathrm{S} 0034-89102005000500001>$.

MAGALHÃES, Carlos A. Teixeira. Criminalidade feminina: um estudo sobre as particularidades do crime praticado por mulheres. De Jure, n. 11, p. 117-143, 2008.

MINISTÉRIO da Justiça. Estudo inédito traça perfil da população penitenciária feminina no Brasil. 04/11/2015 < http:/www.justica.gov.br/noticias/estudo-tracaperfil-da-populacao-penitenciaria-feminina-no-brasil> (4 nov. 2015).

PARSONS, Arthur S. Interpretive sociology: the theoretical significance of Verstehen in the constitution of social reality. Human Studies, v. 1, n. 1, p. 111-137, 1978 $<10.1007 /$ BF02132606>.

PASINATO, Wânia. Questões atuais sobre gênero, mulheres e violência no Brasil. Praia Vermelha, 14-15, p. 130-154, 2006.

PASINATO, Wânia. Lei Maria da Penha: novas abordagens sobre velhas propostas. Onde avançamos? Civitas, v. 10, n. 2, p. 216-232, $2010<10.15448 / 1984-7289$. 2010.2.6484>.

PORTO, Maria Stela Grossi. Crenças, valores e representações sociais da violência. Sociologias, v. 8, n.16, p. 250-273, 2006.

RATTON Jr., José Luiz de Amorim; PORTElla, Ana Paula; GALVÃO, Clarissa; ABATH, Manuela. Análise configuracional de homicídios: Velhas e novas situações de violência letal contra as mulheres em Recife. Dilemas, v. 4, n. 3, p. 403-439, 2011.

ROSENTHAL, Gabriele. Erlebte und erzählte Lebensgeschichte: Gestalt und Struktur biographischer Selbstbeschreibungen. Frankfurt am Main: Campus Verlag, 1995.

ROSENTHAL, Gabriele. Pesquisa social interpretativa: uma introdução. Porto Alegre: Edipucrs, 2014. 
SAFFIOTI, Heleieth I. B. Já se mete a colher em briga de marido e mulher. São Paulo em Perspectiva, v. 13, n. 4, p. 82-91, 1999 <10.1590/S0102-88391999000400009>.

SAFFIOTI, Heleieth I. B. Contribuições feministas para o estudo da violência de gênero. Cadernos Pagu, 16, p. 115-136, 2001.

SANTOS, Hermílio. Adolescents and experiences with violence: making sense of subjective interpretations of life-world. Vibrant, v. 7, n. 2, 2010.

SANTOS, Hermílio (org.). Infância e violência: experiências de violência no cotidiano de crianças em favelas do Rio de Janeiro, Recife e São Paulo. 2014 <www.pucrs.br/ caes> (04 abr. 2016).

SCHÜTZ, Alfred. Theorie der Lebenswelt 1 - Die pragmatische Schichtung der Lebenswelt. Konstanz: UVK, 2003.

SILVA, Luiz Antonio Machado da. Sociabilidade violenta: por uma interpretação da criminalidade contemporânea no Brasil urbano. Sociedade e Estado, v. 19, n. 1, p. $53-84,2004<10.1590 /$ S0102-69922004000100004>.

STAUDIGL, Michael. Towards a phenomenological theory of violence: reflections following Merleau-Ponty and Schutz. Human Studies, 30, p. 233-253, $2007<10.1007 /$ s10746-007-9057-6>.

VASCONCELLOS, Fernanda Bestetti de. A família, a violência e a justiça. Civitas, v. 13, n. 1, p. 136-153, $2013<10.15448 / 1984-7289.2013 .1 .12590>$.

ZALUAR, Alba. Women of gangsters: chronicle of a less-than-musical city. Estudos Feministas, Special issue, 1, p. 109-115, set. 1999.

Recebido em: 18 set. 2015

Aprovado em: 15 dez. 2015

Autor correspondente:

Hermílio Santos

Centro de Análises Econômicas e Sociais - Caes-Pucrs

Av. Ipiranga 6681 - Prédio 50, sala 1005

90619-900 Porto Alegre, RS, Brasil 